\title{
Comparative analysis of oral and computer based types of assessment in teaching English for students of economics, business and finance
}

\author{
Elena V. Grigorieva ${ }^{1}$, Liliya R. Ismagilova ${ }^{1 \mathrm{a}}$ and Irina M. Solodkova ${ }^{1}$ \\ ${ }^{1}$ Kazan Federal University, 4, Butlerov st., Kazan, 420012, Russia
}

\begin{abstract}
Foreign language skill is one of the components highly demanded by employers in the sphere of economics, business and finance. Adequate level of foreign language proficiency can be achieved with a thoroughly selected type of assessment which shows the progresses made by graduates and help to adapt teaching techniques and learning standards to changing requirements. Computer based testing and oral type of assessment are common ways to estimate graduates' foreign language proficiency level. The aim of the present study is to determine the type of assessment which best suits the purpose of higher educational establishment and can be used within graduates' possibilities. Authors came to the conclusion that both CBT and oral type of assessment should constitute the framework of the assessment procedure and be used in their combination because in that way they respond to the needs of higher educational establishment and comply with graduates' differences respectively.
\end{abstract}

\section{Introduction}

Technological economy as well as increased process of globalization determined new requirements to the graduates of higher educational establishments. Higher-order thinking skills together with foreign language skill are said to be the components highly demanded by employers in the sphere of economics, business and finance [10, 12 and 18]. To monitor the level of foreign language proficiency of graduate level students and then assist educators in choosing appropriate teaching techniques and methods, there should be found the suitable type of assessment.

Assessment has always been an essential tool in providing timely feedback and adequate judgement of students' performance. It brings together proper guidance provided

\footnotetext{
${ }^{a}$ Corresponding author: Liliya.Ismagilova@kpfu.ru
} 
by teachers and easy accomplishments of the tasks by students. Proper feedback is "among the most critical influences on students' learning" [6].

It has been reviewed from different international experts that assessment influences "the quality and the level of the students' efforts" [4], and makes "a strong contribution to the improvement of learning [2]. Moreover, assessment is argued to be the tool which helps to "find out whether a particular sequence of instructional activities has resulted in the intended learning outcomes" [16]. Generally, assessment is provided to achieve the following goals:

- collect information about students' progress, learning and development outcomes;

- improve educational programs, curriculum;

- demonstrate program effectiveness;

- show the actual impact the program has on students;

- provide students with evidence of what they have actually learnt;

- meet University annual program reporting and program review requirements;

- address accrediting agency program evaluation requirements;

- diagnose students' particular strengths, weaknesses, difficulties and needs to inform curriculum planning [15].

All HEEs have recently come to the idea that assessment is an ongoing process but only a process of 'evaluating the effectiveness' of completed activities [16].

If with formative assessment (within the course) it is more or less clear, the question of the appropriate type of summative assessment is quite disputable. Preference of a certain type of assessment has to be proved by its effectiveness, by a level of reliability and validity. Furthermore, any type of assessment has to correlate with students' abilities, their physical and psychological condition, etc [3;11]. As it has been observed from the literature, little or no attention is paid to a combination of assessing methods and their hypothetical effectiveness.

The present study describes the importance of finding the suitable type of assessment and its influence on the acknowledgement of a certain language proficiency level proposed by higher educational establishment. The paper compares the contents of CBT and oral type of assessment reviewing the advantages and drawbacks. The authors outline graduates' specific difficulties occurred throughout the assessment procedure and take them as a basis for the experiment to provide a profound study of the matter.

\section{Theory}

Traditionally, all HEEs in Russia used oral assessment as a basic one in summative assessment. Students were supposed to present the contents of the materials they acquired throughout the course of study. Due to the shifts in traditional educational paradigm and the entrance of Russia to the Bologna process, assessment methods were reconsidered. As a result test format exams appeared. Computer-based testing (CBT) became one of those types.

CBT is a kind of assessment that is accomplished with the help of computers. Two main components are required to deliver the test: an assessment engine and an item bank. Since 2004, the Management, Economics and Finance Institute KFU started exploiting CBT. The technical back-up of the project was prepared by institute's IT specialists. As for the item bank, it was supposed that departments of the institute create the item bank of the course they teach. It was revised and supplemented every year. The item bank for taking a final assessment in a foreign language comprised 750 questions, only 100 of them were given to students on the day of their final exam. Final assessment in a foreign language as a subject involved several stages: development of the item bank, approving procedure with institute 
authorities, submission of the whole item bank to the institute library, final e-assessment in computer rooms.

The item-bank for CBT in a foreign language was constructed in the way that it reflected and evaluated all components of the program for students of economics and finance. It was viewed as an objective assessment with one correct answer only. Objective questions included: true/false answers, multiple choice, multiple-response and matching questions.

Certainly, CBT was chosen as an assessment tool because of the advantages over traditional (paper-based or oral) assessment . The advantages include:

- a decrease of workload on teachers;

- facilitation in recording different cognitive skills;

- instant feedback to students;

- less stressful for students;

- deficiency of partiality;

- better reliability (in comparison to human marking);

- possibility of using interactive tasks and multimedia.

Certainly, all mentioned advantages made HEEs introduce this type of assessment and for some of them it became the most common approach. Unfortunately, there were distinguished several drawbacks of using CBT within the described HEE. One of them was inability to check all types of oral communication activity (in particular: listening and speaking) due to technical irregularities. Secondly, it became quite obvious, that some students learnt the material just to pass CBT but not to get real feedback.

The process of reorganization that took place at the HEE in 2014 brought the idea of finding a type of assessment (or a combination of types) suitable for the concrete course and meeting the requirements of all participants involved in it. So, to distinguish an assessment tool that meets educational aims, is relevant to learning outcomes and provides reliable data. Taking into consideration the aim stated in the Syllabus English as a foreign language, that is to prepare a specialist who gains communicative competence at the end of the course [1,5 and 8] it has been decided to organize final assessment orally and compare the results and students attitude to choose proper type of summative assessment.

Oral exam is said to be old but certainly a "traditional practice in some areas of academic life" [7].

Oral assessment, being formerly very popular, provides an assessment of those components, specifically required by the course of English as a foreign language. First and foremost advantage of oral exam is the development of communication skill, which has 'to be explicitly taught and assessed' [17]. Furthermore, oral assessment is more 'authentic' as graduates will face more oral communication rather than written or communication via computer sources [9]. Answering orally, students react to the tasks personally, involving knowledge they gained from different subjects, as well as their experience and emotions. So, oral exam shows students' latitude of thought and breadth of knowledge.

However, current views on oral exam highlighted the idea of impossibility using this type of assessment with certain groups of students, for instance, with those who have some disabilities. It is absolutely inappropriate for students with hearing difficulties, speech impediments and for those who express high level of anxiety. In addition, oral examination better performed by emotional students rather than reserved and introverted ones, as it favors 'the extravert and confident student' [17]. These requirements, along with time consumption and lack of 'abstract reasoning' [7]in taking oral exam are looked upon as drawbacks.

Oral exam, taken at the end of the course in 2014, comprised three components. Though, almost all educational goals were achieved, both teachers and students admit the difficulty of this mode of exam. There was a strong need in research to conduct final exams 
purposefully and then to have an ability to advise HEE's authorities on designing and implementing the effective methods of assessment.

Moreover, the assessment method should correlate with KFU assessment policy, which includes: transparency, summative assessment, validity, special technical resources, and possibility to dispute the results, efficiency, and formative assessment. (Regulations on knowledge scoring and rating assessment system in KFU, Provision on continuous and interim assessment in KFU)

\section{Method}

105 out of 831 third-year students of The Management, Economics and Finance Institute KFU were involved as participants in this research. The sample group was selected from students of different cognitive abilities, score results, language proficiency, computer literacy and both genders that experience both computer-based and oral English exam. 25 members of teaching staff that delivered English to the above-mentioned students and gave their attitude on the basis of their personal experiences through the interview. The aim was to collect data about their attitude toward CB and oral examinations to find out which type of assessment is preferable. Participants' responses were confident and for research purpose only.

The questionnaire comprised 5 questions. Q1 was designed to find out what type of assessment students prefer. Q2 was devoted to the strengths of computer-based and oral English exam. Q3 was aimed at weaknesses of computer-based and oral English exam. Q4 was designed to define preference to oral examination whereas Q5 was designed to define preference of CBT.

\section{Findings}

The responses on the questionnaire were thoroughly analyzed and revealed the following: 31 students (29.5\%) out of 105 showed preferences to CBT and $26(24.8 \%)$ preferred oral assessment. However, 48 (45.7) decided that both types of assessment are important. It has been estimated that students hardly chose any mode of assessment with a slight preference to combined model. (fig.1)

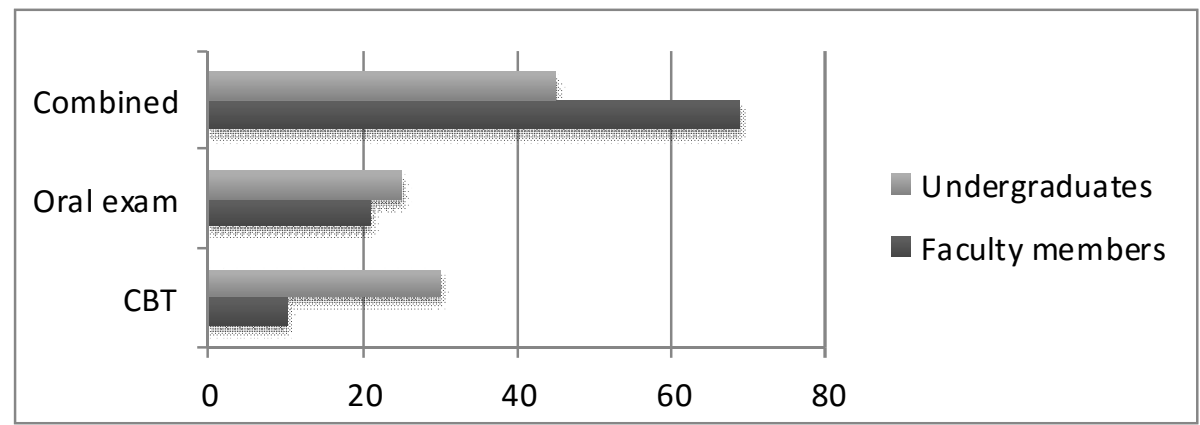

Fig.1. Assessment attitudes.

Q2- 85 undergraduates $(80,9 \%)$ found the CBT is more unbiased, whereas only 57 (54\%) of respondents believed the oral type to be of that kind; $74(70.4 \%)$ felt CBT to be more emotionally comfortable, while 44 (41.9\%) felt unstressed; $82(78 \%)$ thought to manage their time when taking CBT type of exam compared with $80(76.2 \%)$ of those for 
oral exam; 90 (85.7\%) believed that they can manage the process deciding on the order and option on reconsidering the answers with CBT vs 25 (23.8\%) of those preferring oral mode; $73(69,5 \%)$ chose it's easier to dispute the results with CBT type vs $52(49,5 \%)$ with oral mode; assessment criteria are transparent to $91(86.7 \%)$ with CBT and $88(83.8 \%)$ with oral mode; instant scoring was true for $103(98.1 \%)$ - CBT and for $101(96.2 \%)$ - oral; 98 (93\%) admitted that CBT reveals the gaps in knowledge vs $90(85.7 \%)$ that to be true about oral; $53(50.5 \%)$ sought CBT to develop additional skills vs $92(87.6 \%)$ for oral exam; 95 $(90.5 \%)$ thought that CBT gives real summative assessment vs $96(91.4 \%)$ who did the same for oral.

The participants admitted that CBT is more impartial, emotionally comfortable, easier to dispute the results compared with oral mode. It should be noted that transparency of assessment was found important for both exam modes. The majority of undergraduates highlighted summative assessment to be valuable for the exam despite the mode. (fig.2)

Q3 reveals weaknesses of both types: $26(24.8 \%)$ thought that cannot influence the process of CBT mode vs $22(20.9 \%)$ of oral mode; $66(62,9 \%)$ felt stressed with CBT exam vs $93(88.6 \%)$ of oral exam; $39(37.1 \%)$ thought the disputing of the exam results is ineffective with oral exam vs CBT $18(17.1 \%)$; the outcome of the exam is biased with 14 (13.3\%) for CBT and $43(41.0 \%)$ for oral exam; $11(10.5 \%)$ believed the assessment method to be unreliable with CBT and 19 (18.1\%) with oral exam; 5 (4.8\%) students admitted that their computer literacy affected their score with CBT and 13 (12.4\%) found impersonal nature of CBT to be the drawback of CBT mode of examination.

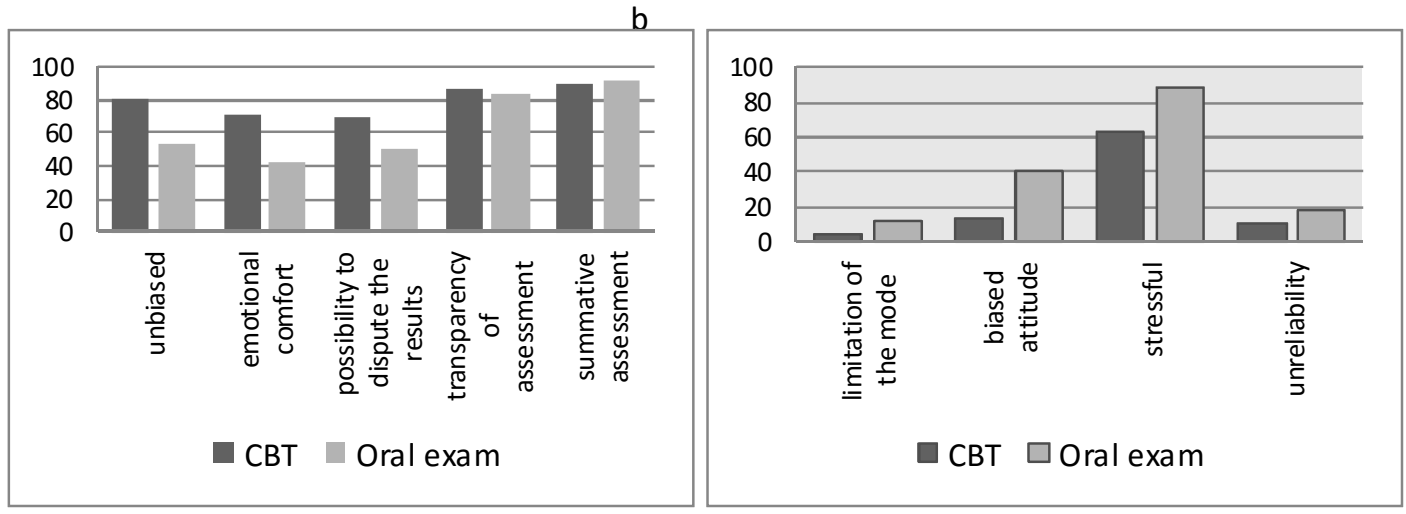

Fig.2. (a) comparative advantages; (b) comparative disadvantages

As for comparative disadvantages of the exams only a small number of undergraduates admitted the limitation of CBT in comparison with oral mode. A third of the sampled group considered oral exam to be more biased compared with CBT mode. CBT was regarded to be less stressful vs oral exam. However, both modes were found reliable by the sampled group. (fig.2)

Q4 and Q5 found out that 32 undergraduates (30.5\%) would like to be assessed orally only whereas $43(41.0 \%)$ preferred to be tested by the computer. $70(66.7 \%)$ would not be satisfied if tested orally only, however, 42 (40.0\%) rejected the CBT mode. $3(2.9 \%)$ did not define their position toward oral exam and 20 (19.0\%) toward CBT.

Whereas faculty members assessment attitudes towards CBT and oral exam is different from undergraduates' one. $21 \%$ gave the preference to the oral exam over $10 \%$ to CBT. However, most of the teaching staff that is almost $70 \%$ found, only combined mode to meet their requirements to final assessment. (fig.1) 
Among the comments during the interview were the opinions that "Oral examination involves additional workload due to the big number of students" and that it's "timeconsuming". While others admitted that "CBT does not develop communicative skills" and is "not objective method".

The majority stated that "Only a combination of modes could demonstrate if all required skills have been formed accordingly".

The results of the research identify that only a combination of two basic exam modes CBT and oral exam appeals to HEE's Assessment Regulations, under graduates requirements and faculty members' course outcome expectations. As it provides proper feedback to students, tracks the formation of all types of oral communication activities (reading, speaking, listening, writing), has optimal workload, allows reliable grading, brings better interpretation of undergraduates' performance, is adaptable to students' differences.

\section{Conclusion}

Research carried out by the authors in real learning environment and the results gained, allowed the authors to conclude that only a combination of two basic exam modes - CBT and oral type of assessment could provide adequate feedback to students and track the formation of all types of oral communication activities (reading, speaking, listening, writing). End-of-the-course assessment should neither add extra workload to teachers nor be too stressful for students aiming, first of all, at acquiring communicative competence. Modification of traditional assessment methods could bring better interpretation of students' performance and allow reliable grading. Moreover, research accomplished within the Management, Economics and Finance Institute KFU, would make it possible for the HEE's authorities to prepare a draft of a final exam which suits the requirements of a modern educational approach.

\section{References}

1. Baklashova, T., Manager's professional training in Russia: Syllabus and technologies // Procedia-Social and Behavioral Sciences, Volume 152, 1057-1061(2014)

2. Black, P. \& Wiliam, D., Assessment and Classroom Learning// Assessment in Education, Vol. 5, No. 1, 1998 (1998)

3. Galishnikova, E., Language learning motivation: A look at the additional program // Procedia-Social and Behavioral Sciences, Volume 152, 1037-1042 (2014)

4. Gijbels, D., Gerard van de Watering \& Dochy, F., Integrating assessment tasks in a problem-based learning environment// Assessment \& Evaluation in Higher Education Vol.30, No. 1 February 2005, 74 (2005)

5. Gorelova, J., Advertising language as a means of forming students' cross-cultural competence // Procedia-Social and Behavioral Sciences, Volume 152, 668-672 (2014)

6. Hattie \& Timperley., The power of feedback // Review of Educational Research 77 (1), 102 (2007)

7. Huxham, M., Campbell, F., \& Westwood, J., Oral versus written assessment: a test of students performance and attitudes// Assessment and Evaluation in Higher Education Vol.3, No.2, 1 (2010)

8. Ismagilova, L., Polyakova, O., The problem of the syllabus design within the competence approach based on the course ,English for Master Degree Students in Economics (advanced level) // Procedia-Social and Behavioral Sciences, Volume 152, 1095-1100 (2014) 
9. Joughin, Dimensions of oral assessment // Assessment \& Evaluation in Higher Education 23: 367, 78 (1998)

10. Khusainova, A., Rahmatullina, A., English language training volunteer program as a new reality for Russia and its social benefits // Procedia-Social and Behavioral Sciences, Volume 152, 1101-1107 (2014)

11. Kudryavtseva, M., Possibilities of distance learning as a means of foreign language learning motivation among students of economics // Procedia-Social and Behavioral Sciences, Volume 152, 1214-1218 (2014)

12. Mardanshina, R., Zhuravleva, E., Model of complementary linguistic education for economists // Procedia-Social and Behavioral Sciences, Volume 152, 1091-1094 (2014)

13. Provision on continuous and interim assessment in KFU // http://kpfu.ru/docs/F1023172663/\%C1\%D0\%D1_02.08.12.pdf(Rus)

14. Regulations on knowledge scoring and rating assessment system in KFU // http://kpfu.ru/portal/docs/F1119174956/tekuschaya.attestaciya.pdf (Rus)

15. Watson, A., Types of Assessment in Education: https://suite.io/amy-watson2/4ztq2mw (An explanation of the different types of assessment used in education and their importance) (2014)

16. Wiliam,D., What is assessment for learning// Studies in Educational Evaluation 37 , 3.

17. Wisker, G. (2004). Developing and assessing students' oral skills. Birmingham: Staff Education and Development Association ( 2011)

18. Zalyaeva, E., Solodkova, I., Teacher-student collaboration: Institute of economics and finance Kazan federal university approach// Procedia-Social and Behavioral Sciences, Volume 152, 1039-1044 (2014) 